\title{
Measurement of Aquatic Biodegradation Rates by Determining Heterotrophic Uptake of Radiolabeled Pollutants
}

\author{
FREDERIC K. PFAENDER* AND GENE W. BARTHOLOMEW \\ Department of Environmental Sciences and Engineering, School of Public Health, University of North \\ Carolina, Chapel Hill, North Carolina 27514
}

Received 30 September 1981/Accepted 5 March 1982

\begin{abstract}
The heterotrophic uptake technique was modified to provide a rapid and simple technique for estimating the rates of biodegradation of organic pollutants under environmental conditions. The methodology is based on an evaluation of uptake into cells and subsequent respiration of radiolabeled organic substrates in shortterm experiments. The resulting data can be used to calculate either turnover times or, if multiple concentrations of substrate are used, kinetic parameters. The procedure was applied to assess the biodegradation rates of $m$-cresol, chlorobenzene, nitrilotriacetic acid, and 1,2,4-trichlorobenzene in fresh, brackish, and marine water samples from the coastal areas of North Carolina. Saturation kinetics for uptake were obtained with each of the compounds tested. Rates of metabolism were shown to be dependent on sample location and time of year.
\end{abstract}

The number of organic compounds introduced into the environment by humans has increased dramatically in recent years. The assessment of the environmental fate of a large number of chemicals would be facilitated by a rapid biodegradation testing method that reflects environmental processes.

The ability of biodegradation studies to predict either rates or products of environmental biodegradation has been questioned (1). Many previous studies have been conducted with pure cultures of microorganisms, in which extrapolation of the results to natural sites with complex microbial communities is tenuous. In experiments with natural communities, concentrations of organic pollutants at levels several orders of magnitude higher than those observed in the environment are often used. Concentration has been shown to significantly influence biodegradation rates $(1,2)$. In addition, long-term confinement of aquatic samples results in increases in the number and metabolic activity of the enclosed microorganisms, as well as changes in the community composition $(3,11)$. These changes may affect estimates of the environmental rates of biodegradation. Recently, several new approaches to studying biodegradation have been proposed. Pritchard et al. (8) have reported on the use of microcosms for investigations of pollutant fate. Although they provide significant information, microcosms are expensive and time consuming and may not provide environmental rates of metabolism. Other studies have based biodegradation rate expressions on chemical measurements of pollutant disappearance and microbial numbers (7), which is an indirect method, or on the mineralization of radiolabeled pollutants (4).

This paper reports on the development and preliminary results of a simple, rapid technique for measuring rates of organic pollutant biodegradation in natural aquatic samples. This method is based on the uptake and mineralization of radiolabeled pollutant substrates; it is similar to the heterotrophic uptake technique that has been used in ecological studies to assess community heterotrophic activity $(6,9,10)$. The amount of substrate incorporated into cellular material and mineralized is measured and can be used to calculate metabolic velocity.

\section{MATERIALS AND METHODS}

Sampling. All aquatic samples were collected in the vicinity of the Newport River Estuary, which is located on the coast of North Carolina about $120 \mathrm{~km}$ southwest of Cape Hatteras. The estuary is small, about $21 \mathrm{~km}^{2}$, and shallow, with an average depth of 1 $m$ at mean low tide. The main freshwater input to the estuary is the Newport River, which drains $340 \mathrm{~km}^{2}$ of forests and swamps and contains no significant sources of anthropogenic organics. The freshwater sampling site is located in the upper area of the Newport River, just south of the town of Newport. The estuarine site is located approximately $10 \mathrm{~km}$ downstream from the freshwater site, in the middle of a broad, shallow expanse of the estuary. The marine sampling site is situated approximately $5 \mathrm{~km}$ offshore. Subsurface samples were collected in 10-liter polyethylene carboys and were returned to the laboratory less than $1 \mathrm{~h}$ after collection.

Isotopes. The following radiolabeled compounds were used as potential substrates in the metabolism studies; $m$-[ring- $U-{ }^{14} \mathrm{C}$ ]cresol (specific activity, 36 $\mathrm{mCi} / \mathrm{mmol}$; Amersham Corp., Arlington Heights, Ill.), 
chloro[U- $\left.{ }^{14} \mathrm{C}\right]$ benzene (specific activity, $19.7 \mathrm{mCi} /$ mmol; Amersham Corp.), nitrilotri[ $\left.1-{ }^{14} \mathrm{C}\right]$ acetic acid (specific activity, $53 \mathrm{mCi} / \mathrm{mmol}$; Amersham Corp.), and $1,2,4$-trichloro $\left[U-{ }^{14} \mathrm{C}\right]$ benzene (specific activity, 13.1 $\mathrm{mCi} / \mathrm{mmol}$; Pathfinder Laboratories, St. Louis, Mo.). Working solutions of each of these chemicals were prepared by dilution in $95 \%$ ethanol to a level of 1 $\mu \mathrm{Ci} / \mathrm{ml}$, with the exception of nitrilotriacetic acid (NTA), which was prepared in a $50 \%$ ethanol-water solution at a concentration of $2 \mu \mathrm{Ci} / \mathrm{ml}$. Working solutions of $\mathrm{D}-\left[U-{ }^{14} \mathrm{C}\right]$ glucose (specific activity, 310 $\mathrm{mCi} / \mathrm{mmol}$; New England Nuclear Corp., Boston, Mass.) and ${ }^{3} \mathrm{H}$-amino acid mixture (New England Nuclear Corp.) were prepared at $1 \mu \mathrm{Ci} / \mathrm{ml}$ in sterile distilled water and $0.01 \mathrm{~N} \mathrm{HCl}$, respectively. These two compounds were used in procedure development experiments. To determine the percent $\mathrm{CO}_{2}$ recovery in the respiration studies, $\mathrm{NaH}^{14} \mathrm{CO}_{3}$ (New England Nuclear Corp.) was utilized.

Experimental design. In the laboratory, the freshwater, estuarine, and marine samples were dispersed in 25 -ml portions in 40 -ml screw-cap vials for $m$-cresol and NTA experiments or in 200-ml portions in 250-ml screw-cap Erlenmeyer flasks for chlorobenzene and trichlorobenzene experiments. Nine incubation vessels were used for each concentration of radiolabeled substrate. All nine vials (flasks) were then amended similarly with the radiolabeled substrate. Three of the amended vials were immediately sealed with plastic caps. These vials were replicates for a direct filtration assessment of metabolic uptake of the substrate in question. All of the other vials were sealed with a Teflon-faced silicon septum (Pierce Chemical Co., Rockford, Ill.) from which was suspended into the vial a plastic cup containing a piece of folded filter paper (Whatman no. 1 chromatography). Three of these samples were replicates for determining the respiration of the radiolabeled substrate. To measure the abiotic uptake and respiration of the substrate, the other three vials were amended with $\mathrm{HgCl}_{2}$ (final concentration, $0.1 \%$ by weight) before being sealed with septa and $\mathrm{CO}_{2}$ traps as described above. All nine incubation vessels were then incubated for 6 to $10 \mathrm{~h}$ at the temperature of the environment from which the samples were collected. After the incubation period, the vials which were sealed with plastic caps were directly filtered through $47-\mathrm{mm}$ membrane filters $(0.2$ $\mu \mathrm{m}$ pore size). The time of incubation was the elapsed time between the addition of labeled substrate and filtration. Polycarbonate filters (Nuclepore Corp., Pleasanton, Calif.) were used with $m$-cresol and NTA as substrates, and cellulose triacetate filters (Gelman Sciences, Inc., Ann Arbor, Mich.) were used with chlorobenzene and trichlorobenzene. After filtering was completed, the incubation flasks and the filters were rinsed with $50 \mathrm{ml}$ of a $50 \%$ ethanol-water solution.

The filters were then placed in scintillation vials containing $11 \mathrm{ml}$ of Aquasol-2 scintillation cocktail (New England Nuclear Corp.) for subsequent counting on a Packard Tri-Carb scintillation counter. To each of the remaining six sample vials $50 \mu \mathrm{l}$ of $2 \mathrm{~N} \mathrm{H}_{2} \mathrm{SO}_{4}$ was added by syringe to the water (final $\mathrm{pH}, 2.3$ ), and 150 $\mu l$ of $1 \mathrm{~N} \mathrm{KOH}$ was added by syringe to the folded filter paper in the cup. In addition, duplicate samples from the three sites were dispensed into appropriate incubation vessels (depending on the substrate used) as described previously, and $0.05 \mu \mathrm{Ci}$ of $\mathrm{NaH}^{14} \mathrm{CO}_{3}$ was added to each vial (flask). These vials were treated similarly and concurrently with the respiration vials. The vials were placed on a rotary shaker $(100$ rpm) for 4 to $6 \mathrm{~h}$, after which time the filter papers were removed, placed in scintillation vials containing $11 \mathrm{ml}$ of Aquasol-2, and subsequently counted. The three samples that were amended with $\mathrm{HgCl}_{2}$ were then filtered and rinsed as described above. The filters were placed in scintillation vials and counted. The efficiency of ${ }^{14} \mathrm{CO}_{2}$ recovery from the samples amended with $\mathrm{NaH}^{14} \mathrm{CO}_{3}$ was used to correct respiration data to $100 \%$ recovery.

Data handling. All scintillation vials were counted for $10 \mathrm{~min}$. Data were corrected by the channels ratio method and converted to disintegrations per minute (dpm). The amount of substrate added to each incubation flask was determined by directly adding to replicate scintillation vials the volume of labeled substrate solution used in the incubations and comparing the radioactivity with the specific activity of the compound. Turnover times $\left(T_{n}\right)$ were calculated by using the incubation time and fraction of added label metabolized (incorporation into cells $+{ }^{14} \mathrm{CO}_{2}$ ) as represented in the following equation:

$$
T_{n}=\frac{T}{f}=T \cdot\left(\frac{\mathrm{dpm} \text { originally added }}{\mathrm{dpm} \text { in cells }+\mathrm{dpm}{ }^{14} \mathrm{CO}_{2}}\right)
$$

where $T$ is the time in hours, and $f$ is the fraction of added label metabolized. Metabolic velocities were calculated by combining substrate concentration with measured metabolism according to Wright (9) and Gocke (5), where:

$$
v=C \times \frac{f}{T}=\frac{C}{T} \cdot\left(\frac{\mathrm{dpm} \text { in cells }+\mathrm{dpm}{ }^{14} \mathrm{CO}_{2}}{\mathrm{dpm} \text { added }}\right)
$$

and $\nu$ is velocity (nanograms per liter per hour), $C$ is the concentration of substrate added (nanograms per liter), and $f$ is the fraction of added label taken up.

\section{RESULTS AND DISCUSSION}

Technique development. The amount of radiolabel taken up into cells was determined by incubating a water sample with a radiolabeled substrate and subsequently filtering the sample, thus retaining microorganisms and any intracellular radiolabeled compounds on the filter. Because the substrate may also adsorb to cell walls, particulate matter, and the filter itself, it was necessary to determine how much label was adsorbed and whether the filter influenced adsorption. By incubating dead cells with various labeled substrates and subsequently filtering the sample, it was found that polycarbonate filters 
TABLE 1. Effect of solvent rinsing after filtering on abiotically adsorbed, radiolabeled $m$-cresol and chlorobenzene in estuarine samples

\begin{tabular}{|c|c|c|c|}
\hline \multirow{2}{*}{ Solvent } & \multirow{2}{*}{$\begin{array}{l}\text { Vol } \\
(\mathrm{ml})\end{array}$} & \multicolumn{2}{|c|}{$\begin{array}{c}\% \text { radioactivity retained on } \\
\text { filter }^{a}\end{array}$} \\
\hline & & $m-$ Cresol $^{b}$ & $\begin{array}{l}\text { Chloroben- } \\
\text { zene }^{c}\end{array}$ \\
\hline No rinse & & $0.80(0.05)$ & $45 \quad$ (1) \\
\hline Distilled water & 25 & $0.53(0.02)$ & $3.0(0.4)$ \\
\hline \multirow[t]{2}{*}{$25 \%$ ethanol } & 25 & $0.25(0.01)$ & $1.2(0.1)$ \\
\hline & 50 & $0.24(0.02)$ & $0.79(0.07)$ \\
\hline \multirow{2}{*}{$50 \%$ ethanol } & 25 & $0.18(0.03)$ & $0.26(0.02)$ \\
\hline & 50 & $0.13(0.01)$ & $0.19(0.01)$ \\
\hline $95 \%$ ethanol & 25 & $0.14(0.02)$ & $0.20(0.04)$ \\
\hline
\end{tabular}

${ }^{a}$ Means of three replicates; parentheses indicate the standard deviation.

${ }^{b}$ Polycarbonate filters $(0.22 \mu \mathrm{m})$ were used with $\mathrm{m}$ cresol.

c Cellulose triacetate filters $(0.20 \mu \mathrm{m})$ were used with chlorobenzene.

gave the least adsorption with the more polar substrates ( $m$-cresol and NTA), whereas cellulose triacetate filters were best with the nonpolar compounds (chlorobenzene and trichlorobenzene). Organic solvents should effectively desorb organic compounds abiotically bound to cells, filters, and glassware if the proper solvent is used. It is important that the solvent employed should desorb organic compounds without disrupting the cells and releasing intracellular contents. To test desorbing solvents, Newport River Estuary water was incubated (25-ml volumes) as for the direct filtration portion of the procedure. The samples were amended with a killing agent $\left(\mathrm{HgCl}_{2}\right.$; final concentration, $\left.0.1 \%\right)$ and either a water-soluble, radiolabeled substrate ( $m$-cresol; $0.053 \mu \mathrm{Ci}$ ) or a water-insoluble, radiolabeled substrate (chlorobenzene; $0.064 \mu \mathrm{Ci}$ ). After incubation for $4.5 \mathrm{~h}$ at $23^{\circ} \mathrm{C}$, the samples were filtered with polycarbonate filters $(0.22-\mu \mathrm{m}$ pore size) for $m$-cresol and cellulose triacetate filters $(0.2-\mu \mathrm{m}$ pore size) for chlorobenzene. The incubation vessel, filter tower, and filters were subjected to various rinse treatments. The results in Table 1 indicate that rinsing with $50 \mathrm{ml}$ of a $50 \%$ ethanol-water ( $\mathrm{vol} / \mathrm{vol}$ ) solution removed almost all adsorbed label, whether the substrate was water soluble or insoluble. Similar results were obtained with radiolabeled trichlorobenzene and cellulose triacetate membrane filters.

To determine whether rinsing with $50 \%$ ethanol would cause cell deformation or lysis, resulting in the leakage of metabolically assimilated label, estuarine water was incubated with either $\left[{ }^{14} \mathrm{C}\right]$ glucose $\left(0.1 \mu \mathrm{Ci}\right.$ per sample) or ${ }^{3} \mathrm{H}$-amino acids $(0.2 \mu \mathrm{Ci}$ per sample). The water samples were then filtered through polycarbonate filters (0.2- $\mu \mathrm{m}$ pore size) and rinsed with either dis- tilled water or one of several concentrations of ethanol in water. The results in Table 2 indicate that rinsing with ethanol at concentrations of $50 \%$ or less did not result in leaching of assimilated intracellular label.

We chose $\mathrm{KOH}$ as a $\mathrm{CO}_{2}$-trapping agent for all compounds under study, as opposed to organic $\mathrm{CO}_{2}$ traps such as ethanolamine or phenethylamine, since these organic compounds tend to absorb some nonrespired, volatilized substrates, leading to inaccurate measurements for respiration. Mercuric chloride was chosen as a killing agent because it effectively inhibits heterotrophic uptake and minimizes cell disruption and leakage of any intracellular label which other killing agents may cause.

Environmental degradation results. The technique described above was evaluated by measuring the uptake and respiration of pollutants at three sites within a coastal environment. Figure 1 shows the velocity of labeled substrate accumulation in cells, respiration, and the two combined (total uptake) for $m$-cresol and chlorobenzene at the midestuary sample site. The term total uptake is used to describe the combined respiration and uptake into cells, since both of these potential fates involve the substrate being taken up by the cells. Uptake and respiration rates were corrected for abiotic factors by means of dead controls. For calculation of biodegradation velocity, we used the concentration of substrate pollutant added as the total concentration present. We made the assumption that the natural concentrations of these substrates are negligible compared to the amount added.

Figure 2 presents the degradation rates of $m$ cresol and chlorobenzene at the three coastal sites. The results suggest that saturation kinetics were obtained, and therefore the data can be plotted (Fig. 3) by using the modified Lineweaver-Burk equation (9). These plots of turnover time versus substrate can be used to calcu-

TABLE 2. Effect of solvent rinsing on the retention of radiolabeled glucose and amino acids in filtered cells

\begin{tabular}{lcc}
\hline \multirow{2}{*}{ Solvent $^{a}$} & \multicolumn{2}{c}{$\%$ label retained on filter $^{b}$} \\
\cline { 2 - 3 } & Glucose & Amino acid \\
\hline Water & 100 & 100 \\
$5 \%$ ethanol & 102 & ND $^{c}$ \\
$25 \%$ ethanol & 103 & 102 \\
$50 \%$ ethanol & 97 & 100 \\
95\% ethanol & 86 & 97 \\
\hline
\end{tabular}

${ }^{a}$ Quantity of rinse was $\mathbf{4 0} \mathrm{ml}$ with glucose-amended samples and $50 \mathrm{ml}$ with amino acid-amended samples.

$b$ Percent label retained $=$ (activity after solvent rinse/activity after water rinse) $\times 100$.

c ND, Not determined. 

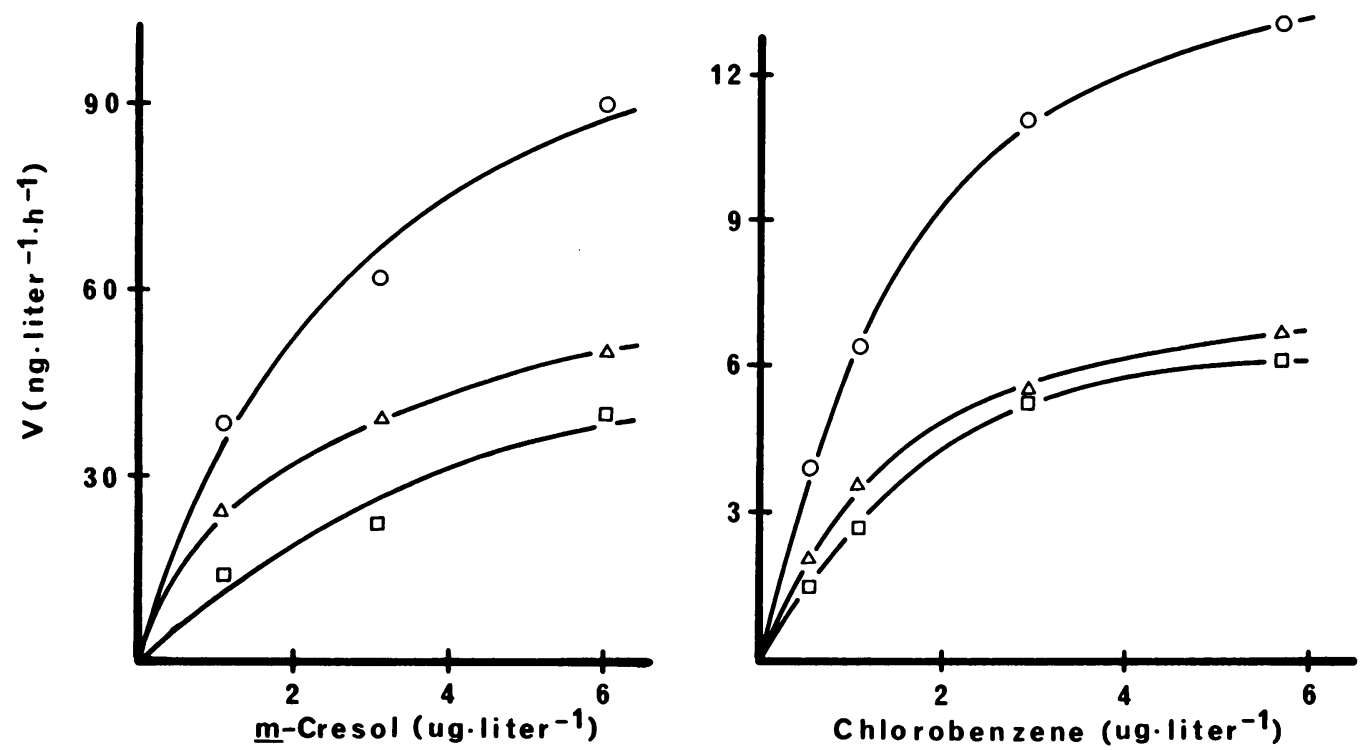

FIG. 1. Metabolic rates of $m$-cresol and chlorobenzene by estuarine microbial community. The velocity (V) of incorporation into cells $(\Delta)$, respiration $(\square)$, and the two combined $(O)$ are shown.

late the maximum velocity of metabolism ( $\left.V_{\max }\right)$ that the microbial community can attain. Total uptake $V_{\max }$ values of 110 (upstream), 20 (estuarine), and 0.98 (marine) ng $\cdot \operatorname{liter}^{-1} \cdot \mathrm{h}^{-1}$ for $m$-cresol and 17 (upstream), 14 (estuarine), and
0.03 (marine) $\mathrm{ng} \cdot \mathrm{liter} \mathrm{r}^{-1} \cdot \mathrm{h}^{-1}$ for chlorobenzene were calculated from these data. With both substrates, the upstream site gave more rapid degradation than the downstream, estuarine area. The marine site had significantly lower
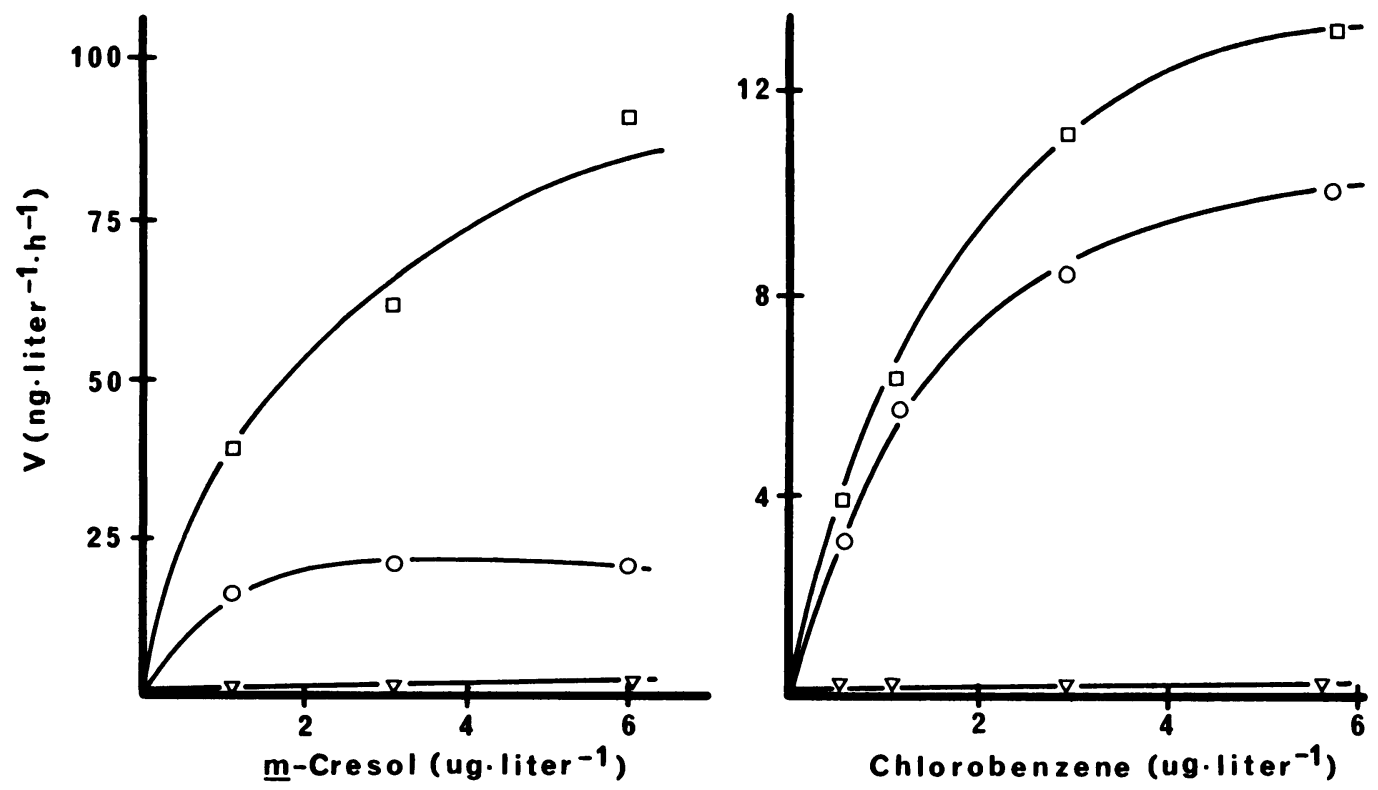

FIG. 2. Metabolic velocity (V) versus concentration plots for $m$-cresol and chlorobenzene at three coastal sites. The upstream site $(\square)$ shows more rapid degradation than the estuarine site $(O)$, which in turn shows more rapid degradation than the marine area $(\nabla)$. 

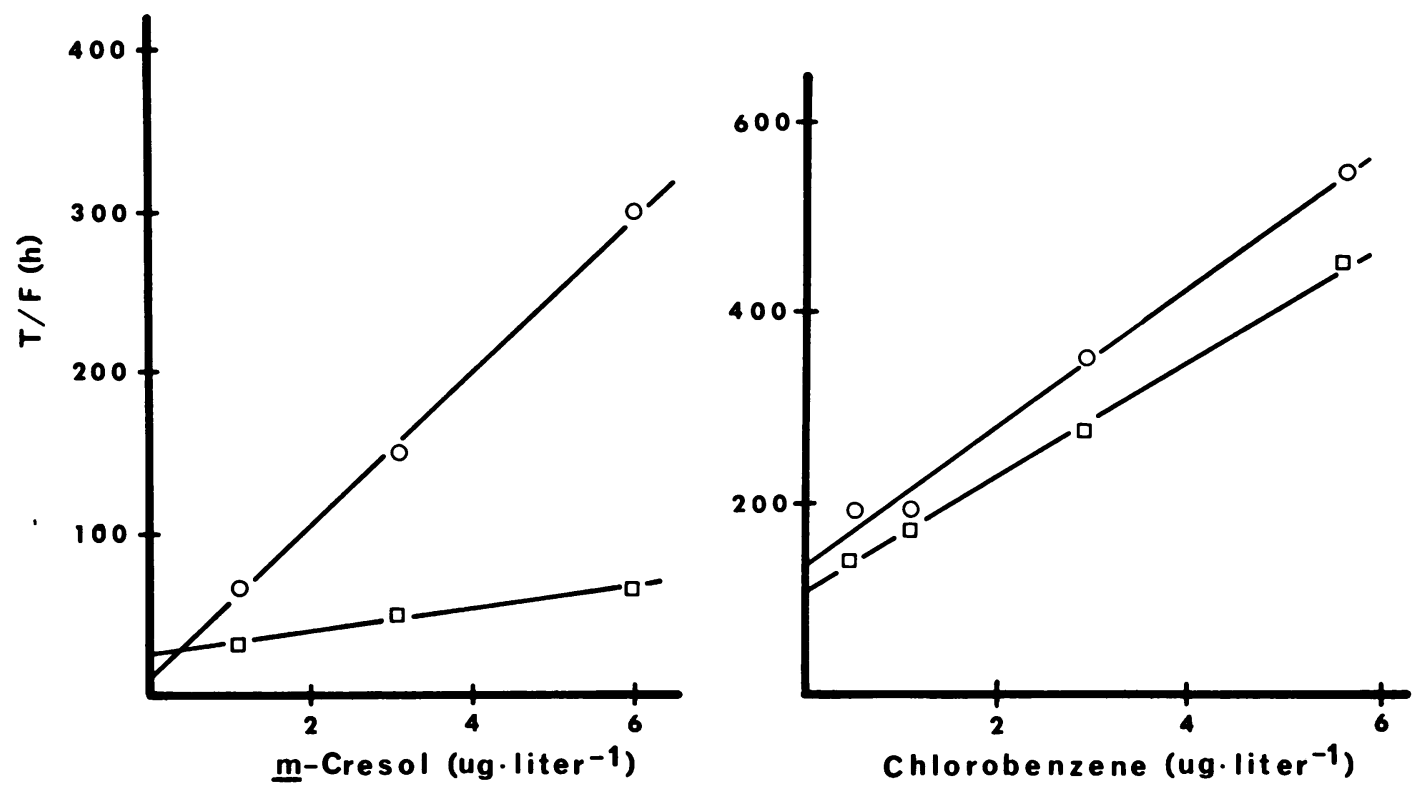

FIG. 3. Lineweaver-Burk plots of total uptake (uptake into cells + respiration) for $m$-cresol and chlorobenzene at estuarine $(O)$ and upstream $(\square)$ sites. The marine site was not included in the plot because the metabolic rates were too low. $T$, Time; $F$, fraction of added label taken up.

metabolic rates than either the freshwater or brackish water areas. The $V_{\max }$ measurement obtained with this technique is most likely an underestimate, since any labeled breakdown products of the substrate which are excreted by the cells are not detected with this method. However, since the production of $\mathrm{CO}_{2}$ from these substrates indicates their utilization for growth, it is unlikely that large amounts of metabolic by-products would be excreted. Although $V_{\max }$ values should be useful for comparing degradation rates at different locations and times of the year or for investigating the influence of environmental variables, caution should be exercised in using these rates to predict persistence. In the natural environment, the concentration present may never be great enough for microbial uptake to reach $V_{\max }$, so this parameter alone would underestimate how long the pollutant might persist.

The technique was used to assess the degradation of several substrates at the estuarine site over a period of almost 1 year. Table 3 presents the metabolic rates obtained from these studies. In each case, saturation kinetics were obtained, so $V_{\max }$ values were included. We also show the turnover rate (inverse of turnover time or fraction of label metabolized per hour) for the lowest substrate concentration added, since this may more accurately reflect degradation conditions that exist in the environment and requires no assumptions about the type of degradation kinet- ics occurring. There were differences between compounds, with degradation rates decreasing from NTA to $m$-cresol to chlorobenzene to trichlorobenzene. The rates were also significantly influenced by the time of year at which the sample was collected. For all compounds, the rates under cold temperature conditions were, as expected, considerably lower than those during warmer temperature periods. Whether these changes were due solely to temperature is not certain, since the annual seasonal cycles involve many changes other than temperature, including nutrient inputs and rainfall.

The main focus of the present research was the development of a relatively inexpensive and rapid biodegradation assessment procedure which is applicable to the study of a variety of organic compounds and provides biodegradation estimates which should be comparable to environmental rates. The technique also provides a metabolic assessment that includes both uptake and respiration. The need for radiolabeled substrates is not a serious deterrent to the use of this technique, since the number of labeled organic compounds readily available is now quite large. The cost of having substrates custom labeled is also relatively small compared to the overall costs of most research projects. The short incubation time eliminates potential interpretation problems that may result from the confinement of the microbial community in containers $(3,11)$. Short incubation times also allow the estimation 
TABLE 3. Kinetic assessment of pollutant metabolism by Newport River Estuary microbial community

\begin{tabular}{lcccc}
\hline Compound & Date & $\begin{array}{c}\text { Temperature } \\
\left({ }^{\circ} \mathrm{C}\right)\end{array}$ & $\begin{array}{c}\text { Turnover } \\
\text { rate }\left(\mathrm{h}^{-1}\right)^{a}\end{array}$ & $\begin{array}{c}\text { Maximum metabolic } \\
\text { velocity } \\
\left(\mathrm{ng}^{\mathrm{liter}}{ }^{-1} \cdot \mathrm{h}^{-1}\right)^{b}\end{array}$ \\
\hline$m$-Cresol & $7 / 22 / 80$ & 26 & 0.0045 & 0 \\
& $8 / 10 / 80$ & 30 & 0.015 & 28 \\
& $10 / 20 / 80$ & 24 & 0.022 & 32 \\
& $12 / 5 / 80$ & 11 & 0.001 & 0.9 \\
Chlorobenzene & $4 / 3 / 81$ & 19 & 0.015 & 0.6 \\
& $7 / 22 / 80$ & 26 & 0.0002 & 14 \\
NTA & $9 / 25 / 80$ & 27 & 0.006 & $<0.1^{c}$ \\
& $2 / 13 / 81$ & 6 & & 850 \\
Trichlorobenzene & $11 / 7 / 80$ & 14 & 0.0013 & 2300 \\
& $2 / 13 / 81$ & 6 & 0.014 & 9.1 \\
\hline
\end{tabular}

a Turnover rate is the reciprocal of turnover time.

${ }^{b}$ Based on uptake plus respiration.

c Below the detection limit of the technique.

of in situ rates of biodegradation and preclude alterations of the community that may influence the rates.

Thus, this method offers the opportunity to evaluate an assortment of chemicals of different structure under the same environmental conditions or to investigate the influence of environmental variables (temperature, community size, nutrient concentrations, etc.) on the rate at which pollutants are metabolized.

\section{ACKNOWLEDGMENTS}

We thank J. Val Klump, Susan D. Levin, Robin Thomas, Kristine Kylberg, David Ruehle, and Eric Stokes for their assistance during several phases of this project. We also thank Battelle Columbus Laboratories and the Office of Toxic Substances, U.S. Environmental Protection Agency, for financial support.

\section{LITERATURE CITED}

1. Alexander, M. 1979. Biodegradation and environmental metabolism of organic pollutants, p. 35-40. In J. M. Witt, J. W. Gillett, and J. Wyatt (ed.), Terrestrial microcosms and environmental chemistry. National Science Foundation (ASRA), Washington, D.C.

2. Boethling, R. S., and M. Alexander. 1979. Effect of concentration of organic chemicals on their biodegradation by natural microbial communities. Appl. Environ. Microbiol. 37:1211-1216.

3. Buckley, E. N., F. K. Pfaender, K. L. Kylberg, and R. L. Ferguson. 1980. Response of the pelagic community to oil from the Ixtoc-I blowout: model ecosystem studies, p. 563-586. In D. K. Atwood (ed.), Preliminary results from the September 1979 Research/Pierce Ixtoc-I Cruise, National Oceanics and Atmospherics Administration, Boulder, Colo.

4. Button, D. K., D. M. Schell, and B. R. Robertson. 1981. Sensitive and accurate methodology for measuring the kinetics of concentration-dependent hydrocarbon metabolism rates in seawater by microbial communities. Appl. Environ. Microbiol. 41:936-941.

5. Gocke, K. 1977. Comparison of methods for determining the turnover time of dissolved organic compounds. Mar. Biol. 42:131-141.

6. Hobbie, J. E., and C. C. Crawford. 1969. Respiration corrections for bacterial uptake of dissolved organic compounds in natural waters. Limnol. Oceanogr. 14:528-532.

7. Paris, D. F., W. C. Steen, G. L. Baughman, and J. T. Barnett, Jr. 1981. Second-order model to predict microbial degradation of organic compounds in natural waters. Appl. Environ. Microbiol. 41:603-609.

8. Pritchard, P. H., A. W. Bourquin, H. L. Frederickson, and T. Maziarz. 1979. System design factors affecting environmental fate studies in microcosms, p. 251-272. In A. W. Bourquin and H. P. Pritchard (ed.), Microbial degradation of pollutants in marine environments. U.S. Environmental Protection Agency, Gulf Breeze, Fla.

9. Wright, R. T. 1974. Mineralization of organic solutes by heterotrophic bacteria, p. 546-565. In R. R. Colwell and R. Y. Morita (ed.), Effect of the ocean environment on microbial activities. University Park Press, Baltimore.

10. Wright, R. T., and J. E. Hobbie. 1965. The uptake of organic solutes in lake water. Limnol. Oceanogr. 10:2228.

11. Zobell, C. E., and D. Q. Anderson. 1936. Observations on the multiplication of bacteria in different volumes of stored seawater and the influence of oxygen tension and solid surfaces. Biol. Bull. (Woods Hole, Mass.) 71:324342. 